Original Article

Artigo Original

Paola Angelica Samuel ${ }^{1}$

Maria Valéria Schmidt Goffi-Gomez ${ }^{1}$

Aline Gomes Bittencourt ${ }^{2}$

Robinson Koji Tsuji ${ }^{1}$

Rubens de Brito ${ }^{1}$

Keywords

Cochlear Implantation Telemedicine

Hearing Loss

Remote Consultation

Descritores

Implante Coclear

Telemedicina

Perda Auditiva

Consulta Remota
Correspondence address:

Paola Angelica Samuel

Hospital das Clínicas da Faculdade de Medicina da USP, R. Dr. Enéas de Carvalho Aguiar, $255,6^{\circ}$ andar, sala 6.167, São Paulo (SP), Brasil, CEP: 05403-000.

E-mail:paolasamuel@gmail.com

\section{Remote programming of cochlear implants}

\section{Teleprogramação dos sistemas de implante coclear}

\begin{abstract}
Purpose: To verify the effectiveness of remote programming of cochlear implants by stimulation levels and results in the perception of speech and free-field audiometry tests. Methods: Twelve patients from both genders, aged between 18 and 59 years, users of internal cochlear implant and speech processor of the same model for at least 12 months, were selected. Both the remote programming (RP) and the live programming (LP) were performed on the same day, measuring the minimum (T) and maximum (C) stimulation levels of five electrodes with the interpolation of the remaining ones. Speech perception tests were applied using $65 \mathrm{dBSPL}$ (recorded open context sentences and monosyllables). The patients were submitted to free-field audiometry at $250-8,000 \mathrm{~Hz}$ frequencies. The results for the RP and LP were compared. Results: Differences in mean of the $\mathrm{T}$ levels for three electrodes and the $\mathrm{C}$ levels for one electrode were found. No difference between the results was obtained in the speech perception tests and audiometric thresholds in the RP and LP. Conclusion: The RP is a simple and effective procedure for programming cochlear implant devices and, although there were differences in the stimulation levels of some electrodes, it did not interfere in the speech perception outcomes.
\end{abstract}

\section{RESUMO}

Objetivo: verificar a efetividade da programação remota do implante coclear por meio dos níveis de estimulação e resultados nos testes de percepção de fala e audiometria em campo livre. Métodos: Foram selecionados 12 pacientes de ambos os gêneros, com idade entre 18 e 59 anos, usuários de implante coclear do mesmo modelo de unidade interna e processador de fala por no mínimo 12 meses. As programações remota (PR) e presencial (PP) foram realizadas no mesmo dia, medindo-se os níveis mínimos (níveis T) e máximos (níveis C) de estimulação de cinco eletrodos, com interpolação dos demais. Foram aplicados testes de percepção de fala (frases em contexto aberto e monossílabos - gravação a 65 dBNPS) e audiometria em campo livre nas frequências de 250 a $8.000 \mathrm{~Hz}$. Os resultados foram comparados entre PR e PP. Resultados: Houve diferença na média dos níveis T em três eletrodos e dos níveis $\mathrm{C}$ em um eletrodo. Não houve diferença entre os resultados obtidos nos testes de percepção de fala e nos limiares audiométricos na PP e PR. Conclusão: A realização da programação remota é simples e eficaz para a programação dos dispositivos de implante coclear e, embora tenha mostrado diferenças nos níveis de estimulação, não interferiu no desempenho da percepção de fala.

Study carried out at Hospital das Clínicas, School of Medicine, Universidade de São Paulo - USP - São Paulo (SP), Brazil.

(1) Cochlear Implant Group, Hospital das Clínicas, School of Medicine, Universidade de São Paulo - USP São Paulo (SP), Brazil.

(2) School of Medicine, Universidade de São Paulo - USP - São Paulo (SP), Brazil.

Conflict of interests: nothing to declare. 


\section{INTRODUCTION}

Telemedicine is the use of the Internet and technology for dissemination of files and information that may assist in health treatments ${ }^{(1)}$. Brazil has seen an increase in incentives to the practice of Telemedicine, such as Programa Telessaúde Brasil Redes, a national action that seeks to improve the quality of primary care in the Unified Health System (SUS), integrating learning and service through information technology tools ${ }^{(2,3)}$.

Teleconsultation is

the application of technology to provide health services at a distance, connecting professionals/clients or professionals/ professionals to provide educational, prevention, diagnosis and intervention services (p. 302) ${ }^{(3)}$.

Through teleconsultation, healthcare professionals can communicate quickly and directly with other professionals or patients, regardless of distance ${ }^{(1)}$.

In the area of audiology, telehealth applies to various situations, such as the development of audiology-oriented teleeducation and teleconsultations ${ }^{(4)}$, remote audiologic diagnostics (through audiometry, otoacoustic emissions and brainstem auditory evoked potential exams) $)^{(5)}$, and remote programming (RP) of electronic devices such as cochlear implant (CI) and hearing-aid devices ${ }^{(3,7-9)}$.

To adjust the optimal stimulation parameters of the $\mathrm{CI}$ for each patient, the programming of the speech processor must be performed periodically. In the programming, one can adjust the level of stimulation and speech processing strategies and make changes according to the needs of each patient ${ }^{(10)}$.

In live programming (LP) sessions, a clinical history check and a survey of complaints are performed, as well as of tests whose results can pinpoint the needs of the new programming. From this information, the programming parameters as chosen, and the precise stimulation levels are determined ${ }^{(11)}$.

In the Cochlear Implant Group of Hospital das Clinicas, School of Medicine, Universidade de São Paulo (USP), users of CI return to perform programming, on average, four to six times in the first year of CI use and semiannually from then on. Several patients using CI, along with their caregivers, need to travel from their home city to the center where they receive care, which involves transportation and accommodation costs, in addition to interfering in their school and/or professional activities. Therefore, the RP of CI systems is a promising resource to decentralize health services, conduct training of professionals in the field of audiology, and possibly reduce costs for SUS ${ }^{(5)}$.

Some studies were conducted using the RP of CI systems. Ramos et al. ${ }^{(12)}$ compared the RP with the LP in five patients for 12 months, with intervals of 3 months between the programming sessions. The sequence of programming was randomized. The authors found no differences in the stimulation levels of the electrodes in pure tone audiometry and speech perception tests held in RPs and directly. They concluded that the RP is feasible, safe, and easy to use, but cannot completely replace face-to-face attendance.
The RP should be used as a support for professionals who are distant or have technical questions.

Zumpano et al. ${ }^{(5)}$ performed RP in two CI users, with the participation of two speech-language pathologists - one, experienced in CI programming, and the other, without such experience, who received the remote support of the experienced professional. Both the CI users and the speech-language pathologists completed questionnaires at the end of the consultations, whose objectives were to verify the advantages, difficulties, and other aspects of the procedure performed. As a result, they concluded that the RP was a viable resource, and participants showed a high degree of satisfaction.

McElveen et al. ${ }^{(13)}$ longitudinally monitored seven CI users, who underwent the RP and the LP for 12 months. The evaluation was done by obtaining audiometric thresholds, sentences in noise (Hearing in Noise Test), and "consonant-vowel-consonant" words (consonant-nucleusconsonant). No differences were observed between test scores and audiometric thresholds in programming conducted in-person and remotely. The authors concluded that the RP is a feasible, safe, and effective procedure, and can be applied to other CI centers, taking this type of care to the poorest areas of the country.

Wasowski et al. ${ }^{(14)}$ verified the effectiveness of RP in 30 patients, also conducting the RP and LP sessions on the same day. At the end of the programming, participants were asked about the quality and reliability of audio and video, performance and effectiveness of RP, comfort during sessions, and the possible reduction in the time and costs of the trip to the place where they received care before. For most participants and professionals, the $\mathrm{RP}$ has been described as an effective method that can facilitate the routine, as well as a safe procedure that is comparable to the LP.

Wesarg et al. ${ }^{(15)}$ conducted a study to evaluate the feasibility, effectiveness, risks, and benefits comparing the RP and LP, using commercial software for video conferencing and remote control for programming the CI. The authors invited $70 \mathrm{CI}$ users to participate in the RP and LP, randomly. No difference was observed in the results between the stimulation levels obtained in both programming situations. The authors concluded that the $\mathrm{RP}$ is a viable alternative to the LP, the procedure can be considered safe, time- and cost-effective, and clinically applicable.

Hughes et al. ${ }^{(16)}$ performed the impedance telemetry, neural telemetry, measurement of stimulation levels, speech perception tests, and administered questionnaires relating to the care received by 29 CI users of two brands. The researchers conducted two direct, in-person sessions and one RP session (direct-remote-direct) to compare the results. The three sessions were held in a mean time of 14 days. No differences were observed in the results, except for a difference in maximum levels between the LP and the RP. The authors concluded that the RP is a viable option for research and clinical care, and that more studies are needed to validate the equipment used.

The objective of this study was to investigate the effectiveness of the RP in CI users, both in the CI's audiological results and the programming parameters in remote and direct conditions. 


\section{METHODS}

This is a prospective, cross-sectional, exploratory study, conducted by the Cochlear Implant Group of Hospital das Clínicas, School of Medicine, USP. It was approved by the institution's ethics committee under protocol number 51702.

The sample was determined by convenience and was constituted by patients who received care from December 2012 to July 2013, who agreed to participate in the study and signed a free and informed consent form.

Inclusion criteria were as follows: patients of both genders, aged between 18 and 59 years, who were CI users for at least 12 months. The internal unit's model was N24R or N24RE and the speech processor's was Freedom SP. Patients also should be able to state the minimum and maximum stimulation levels in programming. Users of the same brand of CI were selected to maintain homogeneity in the evaluation of programming parameters.

The minimum stimulation levels, also called $\mathrm{T}$ levels, are those corresponding to the audibility threshold with CI, whereas the maximum stimulation levels, called C levels, are the highest acceptable levels not to cause discomfort ${ }^{(11)}$.

All participants underwent RP and, on the same day, a new programming was conducted in person in the Specialized Unit (SU). The order of the programming was determined by randomization of the sample, performed with Research Randomizer ${ }^{\circledR(17)}$. In each programming, a new map was made, which the individual only used at the time of the test. This map is the result of the fixed parameters (identical in both situations) and measured levels that determine the amount of current required to generate an audible sensation in each electrode ${ }^{(18)}$.

The programming comprised the following parameters: determination of minimum and maximum stimulation levels ( $\mathrm{T}$ and $\mathrm{C}$ levels) in five interpolated electrodes - electrodes $22,16,11,6$, and $1^{(12)}$, loudness balancing (an adjustment made routinely during CI programming) and adjustments made by voice when needed. If any of these electrodes were deactivated in programming, the adjacent electrode was used. The interpolation of the electrodes is used in clinical practice and establishes the minimum and maximum levels from a sample of electrodes ${ }^{(19)}$.

The other parameters of the programming that compose the map, such as speech coding strategy, speed, and number of maxima, were not modified during the RP and live programming (LP). Parameters already in use by the participants were kept.

The equipment needed for this study were the following:

1. Remote Unit (RU) - presence of an expert audiologist to perform the RP:

- one monitor, for displaying the patient's image;

- one 1-GB RAM notebook, with Microsoft ${ }^{\circledast}$ Windows 7, with Microsoft Office ${ }^{\circledR}$ package;

- Team Viewer ${ }^{\circledR}$ software, for the performance of the remote assistance;

- $\mathrm{Skype}^{\circledR}$ software for the transmission of sound and image;

- one webcam;

- one headset with microphone.
2. Specialized Unit (SU) - presence of the patient and an audiologist to assist in the programming:

- one monitor, for displaying the image of the audiologist at the RU;

- one 1-GB RAM notebook, with Microsoft ${ }^{\circledR}$ Windows 7, with Microsoft Office ${ }^{\circledR}$ package and Custom Sound ${ }^{\circledR}$ software for programming the CI's speech processor;

- one programming interface;

- Team Viewer ${ }^{\circledR}$ software to allow the remote assistance from the RU;

- Skype ${ }^{\circledR}$ software for the transmission of sound and image;

- two speakers;

- one webcam;

- one microphone.

In the SU, one notebook and one video monitor were used, so that the image of the speech-language pathologist was in separate screens from the programming software. Thus, the participant had no visual track of the stimuli given during programming. With the help of the webcam, the audiologist at the RU was able to visualize the participant's facial expression and identify possible situations of discomfort with the stimulation. An audiologist was next to the patient during the entire RP session, making the connection of the speech processor with the interface and reinforcing any guidance given remotely.

The place where the programming (both RP and LP) was done was the same, to maintain the same technological resources and physical space conditions in both situations. The same audiologists performed both programming sessions to avoid biases while obtaining the stimulation levels.

After each programming session, the following tests were conducted:

- Obtaining free-field audiometric thresholds at the following frequencies: 250, 500, 1,000, 2,000, 3,000, 4,000, 6,000, and $8,000 \mathrm{~Hz}$;

- Open-set sentence recognition tests ${ }^{(2)}$;

- Monosyllable recognition test ${ }^{(21)}$, when the percentile of correct answers in the open-set sentence recognition test was equal to or more than $50 \%$.

The open-set sentence and monosyllable recognition tests were applied in a cabin, with recording at $65 \mathrm{dBSPL}$, according to the evaluation protocol for CI of Hospital das Clínicas, School of Medicine, USP ${ }^{(22)}$.

For statistical analysis, the nonparametric Wilcoxon test for paired samples was used. The significance level used was 5\%.

\section{RESULTS}

Twelve CI users who underwent periodical monitoring for evaluation and programming of the device in the Cochlear Implant Group of Hospital das Clínicas, School of Medicine, USP, participated in this study. Seven (58.3\%) were female and five $(41.7 \%)$ were men. The mean duration of use was 33.9 months and the mean age of patients was 43.4 years. 
Of the 12 participants, 7 (58.3\%) initially underwent LP and, shortly thereafter, RP, whereas $5(41.7 \%)$ underwent RP, followed by LP, according to the randomization performed.

In the study of the minimum stimulation levels (T levels), no difference was observed between the levels obtained in the RP and the LP for electrodes 22, 16, and $11(\mathrm{p}<0.05)$, with the current being higher in the RP, with a median difference of six units on electrodes 22 and 11 (Table 1).

In the study of maximum stimulation levels (C levels), the only difference found was in electrode $6(\mathrm{p}=0.014)$, with the current being lower in the RP (Table 2).
No difference was observed between the results of audiometry and speech perception tests when comparing the two forms of programming ( $>0.05$ ) (Tables 3 and 4$)$.

\section{DISCUSSION}

Studies related to the RP of CI systems found in the literature evaluated the differences in the stimulation levels ${ }^{(15)}$, auditory thresholds, and speech perception in $\mathrm{RP}$ and $\mathrm{LP}^{(12,13,16,23)}$ and also assessed the opinion of professionals and participants ${ }^{(5,12,14,16,23)}$.

Table 1. Analysis of the values obtained in the study of the minimum stimulation levels in remote and live programming

\begin{tabular}{lcccccccccc}
\hline \multirow{2}{*}{ Electrodes } & \multicolumn{3}{c}{ LP } & \multicolumn{3}{c}{ RP } & \multicolumn{3}{c}{ Difference (LP-RP) } \\
\cline { 2 - 7 } & Median & Min & Max & Median & Min & Max & Median & Min & Max & p-value \\
\hline E 22 & 111 & 80 & 178 & 118 & 87 & 193 & -6 & -15 & 2 & 0.035 \\
E 16 & 120 & 82 & 188 & 120 & 82 & 189 & -1 & -15 & 1 \\
E 11 & 110 & 84 & 163 & 116 & 90 & 160 & -6 & -13 & 3 \\
E 6 & 115 & 86 & 164 & 114 & 88 & 166 & -1 & -7 & 11 & 0.028 \\
E 1 & 111 & 100 & 170 & 118 & 96 & 173 & -2 & -13 & 10 & 0.658 \\
\hline
\end{tabular}

Caption: $\mathrm{LP}=$ live programming; $\mathrm{RP}=$ remote programming; $\mathrm{Min}=$ minimum; $\mathrm{Max}=$ maximum.

Table 2. Analysis of the values obtained in the study of the maximum stimulation levels in remote and live programming

\begin{tabular}{|c|c|c|c|c|c|c|c|c|c|c|}
\hline \multirow{2}{*}{ Electrodes } & \multicolumn{3}{|c|}{ LP } & \multicolumn{3}{|c|}{$\mathrm{RP}$} & \multicolumn{3}{|c|}{ Difference (LP-RP) } & \multirow{2}{*}{$p$-value } \\
\hline & Median & Min & Max & Median & Min & Max & Median & Min & Max & \\
\hline E 22 & 166 & 135 & 208 & 166 & 135 & 207 & 1 & -9 & 6 & 0.352 \\
\hline E 16 & 178 & 138 & 211 & 172 & 135 & 215 & 3 & -13 & 7 & 0.385 \\
\hline E 11 & 180 & 140 & 218 & 176 & 140 & 216 & 2 & -5 & 9 & 0.154 \\
\hline E 6 & 174 & 132 & 208 & 166 & 129 & 204 & 3 & -2 & 10 & 0.014 \\
\hline E 1 & 183 & 126 & 197 & 180 & 136 & 196 & 3 & -10 & 15 & 0.092 \\
\hline
\end{tabular}

Caption: $\mathrm{LP}=$ live programming; $\mathrm{RP}=$ remote programming; $\mathrm{Min}=$ minimum; $\mathrm{Max}=$ maximum.

Table 3. Results obtained in free-field audiometry after remote programming and live programming, in decibels

\begin{tabular}{|c|c|c|c|c|c|c|c|c|c|c|}
\hline \multirow{2}{*}{$\begin{array}{l}\text { Audiometry } \\
(\mathrm{Hz})\end{array}$} & \multicolumn{3}{|c|}{ LP } & \multicolumn{3}{|c|}{$\mathrm{RP}$} & \multicolumn{3}{|c|}{ Difference (LP-RP) } & \multirow{2}{*}{$\mathrm{p}$-value } \\
\hline & Median & Min & Max & Median & Min & Max & Median & Min & Max & \\
\hline 250 & 35 & 15 & 55 & 37.5 & 15 & 50 & 0 & -10 & 15 & 0.891 \\
\hline 500 & 27.5 & 10 & 40 & 30 & 20 & 40 & 0 & -10 & 5 & 0.317 \\
\hline 1.000 & 20 & 15 & 35 & 20 & 15 & 35 & 0 & -5 & 5 & 0.655 \\
\hline 2.000 & 25 & 10 & 35 & 27.5 & 15 & 35 & -5 & -5 & 5 & 0.096 \\
\hline 3.000 & 32.5 & 10 & 60 & 32.5 & 15 & 55 & 0 & -10 & 25 & 0.483 \\
\hline 4.000 & 30 & 10 & 60 & 40 & 10 & 60 & -5 & -15 & 5 & 0.075 \\
\hline 6.000 & 27.5 & 20 & 55 & 35 & 15 & 50 & -2.5 & -15 & 5 & 0.107 \\
\hline 8.000 & 62.5 & 40 & 130 & 60 & 45 & 130 & 0 & -20 & 10 & 0.666 \\
\hline
\end{tabular}

Caption: $\mathrm{LP}=$ live programming; RP = remote programming; Min = minimum; Max = maximum.

Table 4. Results of speech perception tests after remote programming and live programming, in percentage of correct answers

\begin{tabular}{lcccccccccc}
\hline Speech & \multicolumn{3}{c}{ LP } & \multicolumn{3}{c}{ RP } & \multicolumn{3}{c}{ Difference (LP-RP) } \\
\cline { 2 - 8 } perception & Median & Min & Max & Median & Min & Max & Median & Min & Max \\
\hline Open-set & 90 & 0 & 100 & 90 & 0 & 100 & 0 & -20 & 20 & 0.720 \\
Monosyllables & 38 & 0 & 72 & 44 & 0 & 72 & 0 & -28 & 24 & 0.905 \\
\hline
\end{tabular}

Caption: $\mathrm{LP}=$ direct programming; $\mathrm{RP}=$ remote programming; $M i n=$ minimum; $M a x=$ maximum. 
In this study, all participants underwent RP and LP on the same day, and the order of application was randomized. The randomization was performed carefully to avoid bias in the results, which could be caused by fatigue of the participants throughout the tests. It should be noted that three studies ${ }^{(12,15,16)}$ also mentioned that the participants were randomized.

In the comparison between the RP and the LP, we found that there were differences in the electrodes 22,16 , and 11 on the study of minimum stimulation levels, with higher current values in the RP. In the measurement of maximum stimulation levels, a difference was observed in electrode 6 , showing lower current values in the RP. The study by Hughes et al.(16) also presented a difference in the maximum stimulation levels, which were higher in two electrodes in the RP. The authors attributed this difference to a possible habituation to the signal, because the participants underwent three programming sessions (two direct sessions and one remote session), even if not on the same day.

The study included the presence of two audiologists, present in the SU and in the RU. The same audiologists performed both programming sessions to avoid biases in obtaining stimulation levels. Because one audiologists performed all the RP other one performed all the LP, we believe that the difference found in the stimulation level was not caused by this.

No difference was found between the results of speech perception tests in the RP and the LP. Other studies ${ }^{(12,13,15,16,23)}$ also did not show differences in the results of speech perception tests in both programming situations.

In this study, no differences were found in audiometric thresholds in the RP and the LP. These results corroborate other studies in the literature ${ }^{(12,13,15,16,23)}$, which also did not find differences in audiometry performed in both programming situations.

Although there were differences between the minimum and maximum levels in four electrodes, comparing the two procedures, this variation was, on average, of three to six current units. This difference might not interfere with the patients' speech perception, as was observed in the comparison of the tests performed after the RP and the LP, but might interfere with performance in more difficult situations, such as understanding speech in noise and talking on the phone, which were not included in this study.

Some studies found in the literature ${ }^{(5,12,14,16,23)}$ administered questionnaires to participants to obtain their views on the RP (effectiveness, time, preference, and feasibility of application). This aspect was not measured in this study, as the main objective was to compare the auditory results, speech perception, and programming parameters of the RP and the LP.

The study participants were users of the same brand of CI to maintain homogeneity in the analysis of the parameters. The use of two or more brands in this study could interfere with the comparison of the minimum and maximum levels, because each brand and software have different units of measurement, and also in the analysis of these levels in the interpolated electrodes, because each brand has different numbers of CI electrodes. In the literature, we found studies with other brands of $\mathrm{CIs}^{(12,23,24)}$, which showed that the RP can be applied to different brands available on the market.
In this study, we considered the benefits that the RP can bring to CI users, because many of them travel long distances to get to the Center responsible for programming.

The programming of the speech processor of the CI should be performed periodically - in the first year of use, the programming is held every 3 months and, from then on, users begin to be monitored every 6 months (as long as they have no complaints and difficulties related the use of CI). In a country with large dimensions, such as Brazil, often the patient's travel costs to the CI Center are high, in addition to the time spent by the patient and their family ${ }^{(5)}$. Many patients, especially children, are tired when they arrive to the appointment, interfering with their responses and, consequently, with the final programming established ${ }^{(14)}$.

In Brazil, patients who need specialized public care in a given municipality/state, but who reside in other areas, are entitled to Treatment Outside of Area of Domicile (TDF). TFD was regulated by the Brazilian Ministry of Health in SAS Ordinance No. 55 of 02/24/1999, and is a benefit that provides access to the most appropriate treatment for the health problem ${ }^{(25)}$.

The IC Center in which this study was carried out, located in São Paulo, has over 1,000 CI users. Of these, 53\% reside in the same state. Among the remaining patients serviced in the Southeast, $11.7 \%$ are from Rio de Janeiro, $6.1 \%$ from Minas Gerais, and 3.4\% from Espírito Santo, totaling 21.2\%. In other regions of Brazil, 9.5\% patients are from the South, $5.2 \%$ from the Northern Region, 5.6\% from the Northeast, and 5\% from the Midwest. Therefore, the RP could be used as a resource to reduce government spending on this benefit.

The use of telemedicine and telehealth programs is increasing in Brazil. In 2007, work began on the Projeto Telessaúde Brasil, as an action of Programa Mais Saúde, which defined the use of technology to improve the healthcare service. Teleconsulting, remote diagnostics, tele-education, and formative second opinion are among the services provided (questions originated in teleconsulting are answered based on scientific evidence and revisions of literature $)^{(2)}$.

With the steady growth in the use of technology to benefit the communication between healthcare professionals and the care provided to patients, the Federal Council of Medicine (CFM) ${ }^{(26)}$ and the Federal Council of Speech-Language Pathology and Audiology $(\mathrm{CFFa})^{(27)}$ published resolutions to regulate the use of telemedicine and telehealth in professional practice.

The CFM, in Resolution No. 1.643/2002, published on 08/26/2002 $2^{(26)}$, defined the practice of medicine through telemedicine and telehealth. The resolution highlighted, among other things, the importance of ethics and of information security when providing care and discussing cases via the Internet.

The CFFa, in Resolution No. 427 of 03/01/2013 ${ }^{(27)}$, sets rules for the use of telehealth in Speech-Language Pathology and Audiology. The resolution determined that the professional can provide services such as mentoring other professionals and aiding in the diagnosis and clinical care, as long as the patient agrees to the intervention and that data are transmitted through the Internet safely and confidentially. It also determined that there must always be a registered professional next to the patient during the performance of the remote service. 
Besides the performance of the RP, telemedicine can aid in the training and qualification of professionals, as well as supporting new CI cores. We know that there are limitations, such as difficulty in access to high-speed Internet connection and access to the necessary equipment in more remote regions; however, the RP can be a key resource for the decentralization of health services $^{(5)}$ and training of professionals in the less favored regions.

Ramos et al. ${ }^{(12)}$ emphasized that telemedicine is also effective in emergency cases, in which professionals find problems with equipment (including the operation of the $\mathrm{CI}$, which can be checked at a distance), and when there is demand for the adjustment of the programming by the patient.

Remote care is feasible, safe, and effective, and can be applied to other centers routinely ${ }^{(5,13,14)}$. Studies found in the literature showed that one of the advantages of this practice is that the patient does not need to travel from their city of origin to the CI Center, reducing costs and travel time. Other advantages are the support to professionals who are in remote locations and optimization of the professional's time. However, these aspects were not directly assessed in this study, and may be addressed in future studies on the RP of CI systems.

\section{CONCLUSION}

The RP is a feasible and effective procedure when compared to LP. Although differences were found in stimulation levels between the RP and the LP, there was no difference in the results of speech perception tests and audiometry performed in both procedures.

*PAS was responsible for the collection, tabulation, and analysis of data and drafting of the manuscript; MVSGG collaborated with data collection and supervised the analysis and drafting of the manuscript; $A G B$ collaborated with the data analysis and the drafting of the manuscript; RKT and RB collaborated with the drafting of the manuscript.

\section{REFERENCES}

1. Elangovan S. Telehearing and the Internet. Semin Hear. 2005;26(1):19-25.

2. Portal Telessaúde Brasil Redes [cited 2014 Oct 9]. Available from: http:// www.telessaudebrasil.org.br/

3. Campos PD, Ferrari DV. Telessaúde: avaliação da eficácia da teleconsulta na programação e adaptação de aparelho de amplificação sonora individual. J Soc Bras Fonoaudiol. 2012;24(4):301-8.

4. Bastos BG, Ferrari DV. Internet e educação ao paciente. Arq Int Otorrinolaringol. 2011;15(4):515-22.

5. Zumpano CE, Bevilacqua MC, Frederigue-Lopes NB, Costa OA. Programação remota dos sistemas de implante coclear. Rev Soc Bras Fonoaudiol. 2009;14(3):539-46.

6. Shapiro WH, Huang T, Shaw T, Roland Jr. JT, Lalwani AK. Remote intraoperative monitoring during cochlear implant surgery is feasible and efficient. Otol Neurotol. 2008;29(4):495-8.

7. American Speech-Language-Hearing Association. Survey of telepractice use among audiologists and speech-language pathologists. Rockville, MD: American Speech-Language-Hearing Association; 2002.
8. American Speech-Language-Hearing Association [Internet]. Audiologists providing clinical services via telepractice: position statement [cited 2007 Dec 6]. Available from: http://www.asha.org/docs/pdf/PS2005-00029.pdf

9. Krumm M, Syms MJ. Teleaudiology. Otolaryngol Clin N Am. 2011;44(6):1297-304.

10. Plant K, Holden L, Skinner M, Arcaroli J, Whitford L, Law M, et al Clinical evaluation of higher stimulation rates in Nucleus Reserch Platform 8 System. Ear Hear. 2007;28(3):381-93.

11. Goffi-Gomez MVS, Magalhães ATM. Ativação e Programação do Implante Coclear. In: Bento RF, editor. Tratado de Implante Coclear e Próteses Implantáveis. Rio de Janeiro: Thieme; 2014.

12. Ramos A, Rodríguez C, Martinez-Beneyto P, Perez D, Gault A, Falcon JC, et al. Use of telemedicine in the remote programming of cochlear implants. Acta Otolaryngol. 2009;129(5):533-40.

13. McElveen JTJ, Blackburn EL, Green JDJ, McLear PW, Thimsen DJ, Wilson BS. Remote programming of cochlear implants: a telecommunications model. Otol Neurotol. 2010;31(7):1035-40.

14. Wasowski A, Skarzynski PH, Lorens A, Obrycka A, Walkowiak A, Bruski L. Remote fitting of cochlear implant system. Cochear Implants Int. 2010;11(Suppl 1):489-92.

15. Wesarg T, Wasowski A, Skarzynski H, Ramos A, Gonzalez JCF, Kyriafinis G, et al. Remote fitting in nucleus cochlear implants recipients. Acta Otolaryngol. 2010;130(12):1379-88.

16. Hughes ML, Goehring JL, Baudhuin JL, Diaz GR, Sanford T, Harpster $\mathrm{R}$, et al. Use of telehealth for research and clinical measures in cochlear implant recipientes: a validation study. J Speech Lang Hear Res. 2012;55(4):1112-27.

17. Urbaniak GC, Plous S [Internet]. Research Randomizer (Version 4.0) [cited 2013 Jun 22]. Available from: http://www.randomizer.org/

18. Shapiro WH, Bradham TS. Cochlear implant programming. Otolaryngol Clin North Am. 2012;45(1):111-27.

19. Plant K, Law MA, Whitford L, Knight M, Tari S, Leigh J, et al. Evaluation of streamlined programming procedures for the Nucleus cochlear implant with the Contour Electrode Array. Ear Hear. 2005;26(6):651-68.

20. Costa MJ, Iorio MCM, Mangabeira-Albernaz PL. Desenvolvimento de um teste para avaliar a habilidade de reconhecer a fala no silêncio e no ruído. Pró-fono. 2000;12(2):9-16.

21. Pen MG, Mangabeira-Albernaz PL. Lista de monossílabos para discriminação vocal. In: Mangabeira-Albernaz PL, Ganança MM, editors. Surdez neuro-sensorial. São Paulo: Moderna; 1976.

22. Goffi-Gomez MVS, Guedes MC, Sant'Anna SBG, Peralta CGO, Tsuji RK, Castilho AM, et al. Critérios de seleção e avaliação médica e audiológica dos candidatos ao implante coclear: Protocolo HCFMUSP. Arq Otorrinolaringol. 2004;7(3):197-204.

23. Eikelboom RH, Jayakody DMP, Swanepoel DW, Chang S, Atlas MD. Validation of remote mapping of cochlear implants. J Telemed Telecare. 2014;20(4):171-7.

24. Rodriguez C, Ramos A, Falcon JC. Use of telemedicine in the remote programming of cochlear implants. Cochlear Implants Int. 2010;11(1):461-4.

25. Brasil. Ministério da Saúde. Secretaria de Assistência à Saúde [Internet]. Portaria ${ }^{\circ}$ 55, de 24/02/1999 [cited 2014 Oct 09]. Available from: http:// dtr2001.saude.gov.br/sas/PORTARIAS/Port99/PT-055.html

26. Conselho Federal de Medicina [Internet]. Resolução $n^{\circ}$ 1.643/2002, publicada em 26 de agosto de 2002 [cited 2014 Apr 13]. Available from: http://www.portalmedico.org.br/resolucoes/ CFM/2002/1643_2002.pdf

27. Conselho Federal de Fonoaudiologia [Internet]. Resolução ${ }^{\circ} 427$, publicada em 1 de março de 2013 [cited 2014 Apr 13]. Available from: http://www.fonoaudiologia.org.br/legislacaoPDF/Res\%204272013.pdf 